\title{
Potential and limitations of satellite laser altimetry for monitoring water surface dynamics: ICESat for US lakes
}

\author{
Liu Shu ${ }^{1,2 *}$, Jiang Qigang ${ }^{1}$, Xuesong Zhang ${ }^{3}$, Kaiguang Zhao ${ }^{2,4}$ \\ (1. Department of Geo-exploration Science and Technology, Jilin University, Changchun 130021, China; 2. School of Environment and \\ Natural Resources, The Ohio State University, Columbus, OH 43210, USA; 3. Joint Global Change Research Institute, \\ Pacific Northwest National Laboratory, College Park, MD 20740, USA; 4. Ohio Agricultural and Research Development Center, \\ School of Environment and Natural Resources, The Ohio State University, Wooster, OH 44691, USA)
}

\begin{abstract}
Elevation measurements from the Ice, Cloud and Land Elevation Satellite (ICESat) have been applied to monitor dynamics of lakes and other surface water bodies. Despite such potential, the true utility of ICEsat--more generally, satellite laser altimetry--for continuously tracking surface water dynamics over time has not been adequately assessed, especially in the continental or global contexts. This study analyzed elevation derived from ICESat data for the conterminous United States and examined the potential and limitations of satellite laser altimetry in monitoring the water level dynamics. Owing to a lack of spatially-explicit ground-based water-level data, the high-fidelity land elevation data acquired by airborne lidar were firstly resorted to quantify ICESat's ranging accuracy. Trend and frequency analyses were then performed to evaluate how reliably ICESat could capture water-level dynamics over a range of temporal scales, as compared to in-situ gauge measurements. The analytical results showed that ICESat had a vertical ranging error of $0.16 \mathrm{~m}$ at the footprint level—an lower limit on the detectable range of water-level dynamics. The sparsity of data over time was identified as a major factor limiting the use of ICESat for water dynamics studies. Of all the US lakes, only 361 had reliable ICESat measurements for more than two flight passes. Even for those lakes with sufficient temporal coverage, ICESat failed to capture the true interannual water-level dynamics in $32 \%$ of the cases. Our frequency analysis suggested that even with a repeat cycle of two months, ICESat could capture only $60 \%$ of the variations in water-level dynamics for at most $34 \%$ of the US lakes. To capture $60 \%$ of the water-level variation for most of the US lakes, a weekly repeated cycle (e.g., less than $5 \mathrm{~d}$ ) is needed - a requirement difficult to meet in current designs of spaceborne laser altimetry. Overall, the results highlight that current or near-future satellite laser missions, though with high ranging accuracies, are unlikely to fulfill the general needs in remotely monitoring water surface dynamics for lakes or reservoirs.
\end{abstract}

Keywords: ICESat, lidar, water resources, lake dynamics, water level, satellite laser altimetry, lake surfaces, repeat cycle DOI: $10.25165 /$ j.ijabe.20171005.3426

Citation: Liu S, Jiang Q G, Zhang X S, Zhao K G. Potential and limitations of satellite laser altimetry for monitoring water surface dynamics: ICESat for US lakes. Int J Agric \& Biol Eng, 2017; 10(5): 154-165.

\section{Introduction}

Lakes and reservoirs are key components of regional and global water cycles, serving important roles in water resources management over human-dominated landscapes.

\section{Received date: 2017-04-13 Accepted date: 2017-08-29}

Biographies: Jiang Qigang, $\mathrm{PhD}$, Professor, research interests: geo-science analyses of RS, Email: jiangqigang@jlu.edu.cn; Xuesong Zhang, $\mathrm{PhD}$, Reseach Scientist, research interests: hydrology, watershed modeling, and earth system sciences, Email: Xuesong.Zhang@pnnl.gov; Kaiguang Zhao, PhD, Assistant Professor, research interests: GIS analysis for environmental and
For example, they hold the third largest amount of fresh water ${ }^{[1]}$, and serve critical sources of clean water to human and the wildlife ${ }^{[2]}$. Lakes, especially their extents and water quantities, are directly affected by climatic and anthropogenic drivers and the health of lake ecosystems is found to be sensitive to climatic changes

engineering applications, Email: zhao.1423@osu.edu.

*Corresponding author: Liu Shu, PhD candidate, research interests: application in remote sensing of environment. Department of geo-exploration science and technology, Jilin University, No.938, Ximinzhu Street, Changchun 130021, China. Tel: +86-13843177926; Email: liushu8877@126.com. 
and watershed management activities in many regions of the world ${ }^{[3-5]}$. Given the ecological and environmental roles of lakes and other surface water bodies, there has long been a recognized need for monitoring their temporal dynamics ${ }^{[6]}$. One of the major indices used for monitoring purposes is water levels, which is observed to be particularly sensitive to climatic variations and is deemed as a reliable proxy in predicting lake water volumes $^{[7-9]}$. Monitoring water level fluctuations, therefore, will help to track lake dynamics and correspondingly aid in better managing and conserving water resources ${ }^{[10]}$.

Water-level fluctuations have been traditionally measured in-situ at selected locations with a gauge station $^{[11]}$. Similar to other ground-based environmental monitoring technologies, a wide deployment of gauge stations is infeasible and can be hindered by many practical factors. Foremost, installation and maintenance of gauge stations are expensive and the data collection is also labor-intensive. The costs will become prohibitive if targeting at lakes and surface waters in remote regions characterized by harsh climatic and topographic conditions. These logistics constraints make it impossible to conduct gauge measurements regularly for extensive regions ${ }^{[12]}$. Current gauge data of lake water levels are limited only at isolated points for a very small fraction of lakes and surface waters.

Limited spatial footprints of gauge stations can be extended by pursuing remote sensing-based approaches, especially with the use of satellite altimetry. Radar altimeters are among the first generation of spaceborne sensors employed to detect water-level variations ${ }^{[13]}$. An early example is the ERS-1, launched in $1991^{[14]}$. Thus far, radar altimetry data have been acquired by an array of spaceborne systems such as Jason-1/2, ERS-1/2, CFO, Topex/Poseidon and EnviSat ${ }^{[11]}$. In particular, after the decommission of Topex/Poseidon in 2005, Jason-1/2 acted as successors because they shared the orbit with Topex/Poseidon. Similarly, ERS and Envisat also formed pairs ${ }^{[15]}$. The combination of these different spaceborne radar altimetry data generated long-term measurements of surface elevation with enhanced capabilities for monitoring surface dynamics. However, satellite radar altimetry has its own weaknesses. The existing systems, for example, differed from each other in terms of temporal and spatial resolutions, engendering inconsistency and bias in long-term monitoring ${ }^{[14]}$. An even more critical weakness is the coarse spatial resolution of satellite radar altimetry, often with a diameter of several kilometers, therefore limiting the use of radar altimetry to only large water ${ }^{[10]}$.

Recent advances in laser ranging brought laser-based altimetry into the arena of earth science applications ${ }^{[15-19]}$. Up to the writing, the first and the only satellite laser altimeter explicitly targeted at tracking surface elevation dynamics is the Ice, Cloud, and Land Elevation Satellite (ICESat $)^{[14]}$, carrying the Geoscience Laser Altimeter System (GLAS) onboard. It was launched on January 12, 2003, and was decommissioned in 2009 due to instrument failures ${ }^{[20]}$. A major goal of ICESat is to measure changes in elevation over glaciers and lands for estimating ice sheet mass balance or predicting canopy change and carbon dynamics ${ }^{[21,22]}$. The laser altimeters on ICESat emitted laser pulses to detect land surface. Shooting up to 40 pulses per second, GLAS imprinted a track of footprints, approximately $70 \mathrm{~m}$ in diameter, on land surfaces every $172 \mathrm{~m}$. After received the echo pulses, ICESat acquired ranging data and other situation information of sample spots ${ }^{[23,24]}$. The high precision in laser ranging achieved by ICESat further contribute to its successes for a range of land dynamics applications ${ }^{[11]}$.

The usefulness of ICESat for detecting variations in surface water bodies has been exemplified in a few pilot studies. Chipman and Lillesand, for example, monitored the water level variations of large lakes in the Toshka Depression of southern Egypt and provided initial evidence on the power of ICESat data to study regional-scale hydrologic processes ${ }^{[25]}$. Several studies focused on the Tibetan Plateau and used the Moderate Resolution Imaging Spectroradiometer (MODIS) data to derive water masks and extract ICESat footprints within the closed lakes or reservoirs to monitor the trends in lake water $^{[6,7,12]}$. Wang et al. ${ }^{[8]}$ recently applied ICESat to the full extent of China and proposed a robust method to extract the water level without applying data masks. In France, Baghdadi et al. ${ }^{[26]}$ evaluated the ICESat data for 
rivers and noted smaller errors in ICESat measurements for wider rivers. In the US, Hall et al. ${ }^{[27]}$ evaluated the accuracy of ICESat data for the Mississippi and Danube rivers and reported that their results were improved significantly when excluding ICESat data with saturation. Although the ICESat mission ended in February 2010 due to instrument failures, its utility for monitoring changes in water level at high spatial resolutions has been demonstrated and initially confirmed by these pilot studies. The existing empirical evidence and the resulting ICESat water level data also serve as baselines for future satellite laser altimetry mission, such as ICESat- $2^{[6,12]}$

Despite the initial successes exemplified in the use of ICESat to monitor surface waters, challenges remain, with some critical uncertainties and gaps to be addressed. As examples, most existing studies focused on local and regional scales or considered only large lakes and reservoirs ${ }^{[6,8,15,24]}$. The real potential of ICESat-like data for detecting water-level dynamics in more general settings are unclear, especially regarding its applicability at the global scale ${ }^{[28]}$. Also, caveats exist in ICESat data processing, still with room to improve in ICESat data quality assurance and screening. More specifically, ICESat/GLAS laser signals represent an integration of numerous factors in a complex way. Not all laser data are equally useful in characterizing surface elevation. The level of successes achieved with ICESat-based monitoring therefore hinges largely on the way how to maximally tap the information from some noisy. Further, the full utility of ICESat data for monitoring water surface dynamics can be attained only if fusing other remote sensing data. Many existing studies chose to use coarse-resolution MODIS data. The low spatial resolutions add additional uncertainties confounding the analyses. High-resolution products, such as those from Landsat, represent a valuable data source for augmenting the efficacy of ICESat. Moreover, compared with terrestrial landscapes, lakes are dynamical, changing rapidly. Even with a higher temporal resolution than other satellites, it remains unclear as to how much of the water-level dynamics can be captured by ICESat for most lakes in the world.
The overall objective of this study is to examine to what extent ICESat or more generally, satellite laser altimetry can be successfully used to measure water-level dynamics over time. One specific goal is to test how well ICESat has captured long-term trends in water levels during its lifespan. ICESat has a low repeat frequency and is unlikely to detect rapid, short-term dynamics; therefore, another specific question to be answered here is what are the revisit periods required of ICESat-like systems in order to monitor water-level dynamics at a given confidence level. To address these goals, the vertical ranging accuracy of ICESat was evaluated firstly. Then, we obtained ICESat data for the conterminous United States, analyzed all the footprints falling into lakes, as determined from a Landsat $30 \mathrm{~m}$ water mask, and conducted both trend and frequency analyses to evaluate the potential and limitations of ICESat data for monitoring water-level dynamics.

\section{Materials and methods}

Our study area is the conterminous United States. Data from various sources were combined to aid in the processing and analyses of ICESat data. In particular, a Landsat-based water mask was acquired to delineate lakes at 30-m resolution. High-precision DEM data from airborne laser scanner was compiled as references to evaluate the ranging accuracies of ICESat over water surfaces. In this evaluation, a low-relief, plain region near Champaign, IL was purposefully chosen as a surrogate to water surfaces. Our ground-truth data of lake water levels are gauge observations measured at isolated points in lakes across the US. We compared the ICESat and gauge data in a trend analysis using linear regression and characterized water-level dynamics using a special Fourier transform spectral analysis technique to estimate the revisits periods desired for ICESat-like systems. Below, we detailed the various data used and analyses conducted.

\subsection{ICESat data}

Satellite laser altimetry data were downloaded from the National Snow and Ice Data Center (NSIDC) website (ftp://n5eil01u.ecs.nsidc.org/SAN/GLAS). The particular product acquired is ICESat's Level-2 data, that is, 
GLAH14 Release-34. GLAH14 contains the surface elevation data and is referenced in the WGS84 coordinate system $^{[29]}$. Each GLAH14 file was a collection of records of ICESat footprint measurements on a certain day. Each record contains a number of parameters describing the elevation and ephemeral status of one laser shot. All 18 campaigns from 2003 to 2009 were included in our analyses.

\subsection{Water mask}

The water mask chosen here is a $30-\mathrm{m}$ binary map recently developed by the University of Maryland from mosaics of numerous Landsat-7 scenes (http://earthenginepartners.appspot.com/science-2013-glo bal-forest $)^{[2]}$. The spatial resolution of the mask is smaller than ICESat's $70 \mathrm{~m}$ footprints, thereby enabling us to resolve sub-footprint surface features and confidently remove non-lake footprints or those footprints with mixed surface covers. This mask has three values: "0" for no data, "1" for lands, and "2" for water bodies such as rivers, lakes, reservoirs and oceans. A morphological operator was applied to the mask to identify connected pixels of the same value and delineate individual regions of interest. Geometric parameters of each delineated region were computed, for example, including area, shape factor, irregularity, length, width, and distance to oceans, and they were used as criteria to exclude non-lake water bodies. Each lake identified was labelled with a unique ID and provided the base layer to filter out those footprints falling into lakes or reservoirs.

\subsection{Gauge data of water levels}

In-situ water-level measurements were obtained from the USGS's data portal (http://maps.waterdata.usgs.gov/ mapper/index.html). Only those gauge stations with more than three years' continuous measurements and with the type of 'lake' were considered here, giving rise to a total of 908 lakes and reservoirs for our analyses.

The gauge-based water level data were to be used for two types of analyses. Firstly, for those lakes have coincident ICESat data and gauge measurements of elevations, multi-year trends were derived and compared between ICESat and gauge data. Secondly, all the gauge data were used for frequency analysis to estimate the ideal temporal resolution of satellites.

\subsection{Airborne lidar DEM}

To assess the vertical ranging accuracy of ICESat, we complied high-precision airborne lidar DEM data for a flat area located in the southern part of the Champaign, IL $\left(39^{\circ} 52.62^{\prime} \mathrm{N}-40^{\circ} 1.02^{\prime} \mathrm{N}, 88^{\circ} 12.18^{\prime} \mathrm{W}-88^{\circ} 17.32^{\prime} \mathrm{W}\right)$. The choice of a flat land region, on one hand, circumvents the need for spatially-explicit in-situ water-level data, which are almost nonexistent, and, on the other hand, minimizes the confounding effects of underlying terrain, as contrasted to previous studies focused mostly on forested landscapes with complex terrain. Two airborne Lidar DEM tiles were obtained from the National Elevation Dataset (http://viewer.nationalmap.gov/basic/). Both represent the elevation of bar terrain in reference to the North American Vertical Datum of 1988 (NAVD88) and have a spatial resolution of 1 meter. The normal error of the airborne lidar DEM is less than $10 \mathrm{~cm}$ measured by Root Mean Square Error $(\mathrm{RMSE})^{[30]}$, therefore serving a reliable source to check the accuracy of satellite laser altimetry ${ }^{[31]}$.

\subsection{ICESat data processing}

The ICESat data usually contained outliers. The values of some quality flags of outliers were different from the high quality data. Fourteen parameters for each ICESat/GLAS record were extracted to remove the outliers and calculate elevation of lake surfaces ${ }^{[32]}$, as summarized in Table 1. In brief, if the sat_corr flg value is no more than three, the elevation of the record is contaminated by saturation effect. Saturation usually occurs when the footprints are located on the flat land surface such as ice and water. Strong reflected echoes cause pulse distortion and result in underestimation of detected elevation ${ }^{[23,32]}$. To correct the saturation effect, the saturation correction parameter, d_satElevCorr, was further used for screening and filtering footprint-level elevations. Of other important GLAS parameters, i_numPk is the number of Gaussian peaks in the waveform. For the footprints covering the region of lakes or reservoirs, the value of $i$ numPk should be one. d_reflct $U C$ is the reflectivity, not corrected for atmospheric effects. In our analyses, those footprints with d_reflct UC greater than 0.9 were considered contaminated and the associated elevations were excluded. 
elv_cloud_flg indicates whether the surface elevation is contaminated by cloud. sigma_att_flg is the attitude quality flag. If its value is more than 50 , the elevation data are in bad quality.

Table 1 Parameters used in this study and their descriptions

\begin{tabular}{|c|c|}
\hline Parameter & Description \\
\hline d_elev & The elevation above the reference ellipsoid. \\
\hline d_lat & The geodetic latitude \\
\hline d_lon & The geodetic longitude \\
\hline i_numPk & The number of Gaussian peaks in the waveform. \\
\hline sat_corr_flg & Saturation Correction Flag \\
\hline d_satElevCorr & Saturation Elevation Correction added to surface elevation \\
\hline sigma_att_flg & Attitude quality flag \\
\hline d_reflct $U C$ & $\begin{array}{l}\text { The reflectivity, division of the received energy and the } \\
\text { transmitted energy }\end{array}$ \\
\hline elv_cloud_flg & Cloud contamination flag \\
\hline d_SigBegOff & The signal begin range increment \\
\hline d_SigEndOff & The signal end range increment \\
\hline$d \_g d H t$ & $\begin{array}{l}\text { The height between EGM96 geoid and Topex/Poseidon } \\
\text { ellipsoid }\end{array}$ \\
\hline d_deltaEllip & $\begin{array}{l}\text { The difference between Topex/Poseidon ellipsoid and WGS } 84 \\
\text { ellipsoid }\end{array}$ \\
\hline d_gpCntRngOff & Centroid Range Increment for Gaussian peaks \\
\hline
\end{tabular}

The procedure for selecting footprints was divided into four steps. Firstly, by setting thresholds for parameters of GLAH14 products, the obvious outliers were excluded such as noises, the shots with extremely high or low elevation, saturation effects, multiple Gaussian peaks, low latitude quality, and high reflectivity, gain value as well as elevation on errors ${ }^{[8,12]}$. Secondly, by overlaying the water mask to the remaining ICESat data, the footprints located within the boundaries of lakes and reservoirs were extracted completely. Thirdly, calculating the standard deviation of these extracted footprints, and the footprints causing an abnormally high standard deviation were removed. Lastly, for the lakes with small islands in them, the footprints on the islands were removed by visual check. The remaining footprints were regarded as the ones with good quality and used in the subsequent processes. The workflow for selecting the footprints is shown in Figure 1.

Lake level corresponded to the distance between the lake surface and the geoid height ${ }^{[33]}$. As the d_elev values were referenced to the Topex/Poseidon ellipsoid and EGM96 geoid, they were converted to the WGS84 ellipsoid elevations using the parameter $d$ gdHt and d_deltaEllip. The final elevation (Elev) of each footprint was derived from the following formula:

$$
\begin{aligned}
\text { Elev }= & d_{-} \text {elev }+d_{-} \text {satElevCorr }- \\
& d_{-} g d H t-d_{-} \text {deltaEllip }
\end{aligned}
$$

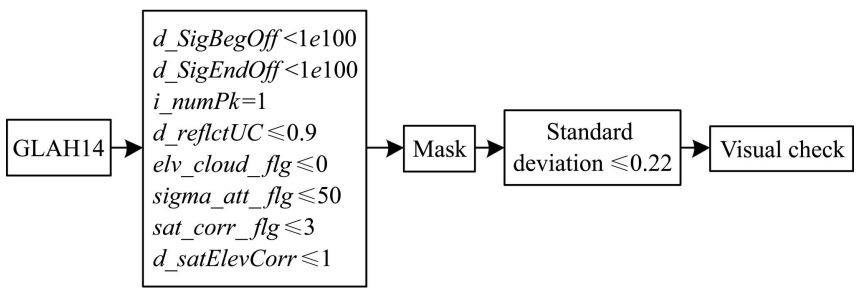

Figure 1 A customized workflow for screening, filtering, and identifying high-quality ICESat/GLAS footprint-level elevation data. Variables listed here are standard parameters of GLAS14 products

As the footprints within the same lake or reservoir were not exactly in the same position, the elevations acquired would have small geoid differences, which could not be ignored. The mean elevations of all the footprints on the same date within the same lakes were computed to eliminate small geoid errors ${ }^{[12]}$. These mean values were the lake elevations derived from GLAH14.

When compared with Lidar DEM, the effects from land cover must be taken into consideration. In this part, the footprints with multiple Gaussian peaks were not regarded as outliers. The lowest Gaussian peak represented the ground return. Three more parameters, d_SigBegOff, d_SigEndOff and d_gpCntRngOff were used to get the ground elevation, which (GElev) could be expressed as:

$$
\begin{aligned}
\text { GElev }= & \text { Elev }-d_{-} g d H t+0.5\left(d_{-} \text {SigBegOff }+\right. \\
& \left.d_{-} \text {SigEndOff }\right)-d_{-} \text {gpCntRngOff }
\end{aligned}
$$

where, Elev shares the same meaning with the one in Equation (1).

\subsection{Accuracy assessment of ICESat elevation}

We followed a procedure similar to that of reference [34] to assess the vertical accuracies of ICESat. This procedure explicitly addressed the discrepancy in spatial resolutions between ICESat's footprint and airborne lidar DEM by adopting a weighted-averaging scheme. Multiple pixels of lidar DEM covered by the same footprint were weighted in the averaging to get the mean reference elevation for each footprint. The comparison may be confounded by the temporal discrepancy as well ${ }^{[34]}$. To minimize the time gap, the airborne lidar DEM data was chosen for April 16, 2008 and the ICESat 
data acquired on October 4, 2008 was used. A third discrepancy we corrected is the difference in vertical datum, that is, NAVD88 for airborne lidar $v s$. the TOPEX/Poseidon ellipsoid for ICESat.

GLAH14 elevation was transformed to the NAVD88 heights using "NOAA's vertical Datum Transformation-v3.4" software. The standard derivation of the transformation is $2 \mathrm{~cm}$. The resulting elevations derived from ICESat were evaluated against lidar DEM in terms of Pearson's correlation coefficient $(R)$ and RMSE.

\subsection{Trend analysis of water-level dynamics}

As in Section 2.2, elevations of all the lakes within the conterminous US were extracted from ICESat/GLAH14. Linear regression was applied to the lakes with two or more ICESat tracks. Slopes from the regression indicate the lake level dynamic trends. For the lakes with more than one ICESat passes, the concomitant gauge data were used to validate the trends derived from GLAH14. In our trend analyses, we differentiated two types of gauge data. The gauge data from February 20, 2003 to October 20, 2009 were represented by Gau1. The gauge data got exactly on the same date as the ICESat passes were represented by Gau2. Linear regression was based on both Gau1 and Gau2; the resulting slopes are denoted by Trend1 and Trend2, respectively.

\subsection{Frequency analysis to determine revisit cycles}

Frequency analysis to all the gauge water-level data was performed using the discrete Fourier transform. The purpose is to identify dynamic patterns of gauge data at a range of temporal scales in attempt to determine the minimum requirement for revisit cycles for satellite altimetry. The discrete Fourier transformation can convert gauge time-series data from the time domain $\left[X_{1} \ldots X_{N-1}\right]$ to frequency domain $\left[A_{1} \ldots A_{N-1}\right]$ by decomposing the time-series into a sum of harmonic functions.

$$
X_{t}=\sum_{k=0}^{N-1} A_{k} \cdot\left(\cos \left(2 \pi k \frac{t}{N}\right)+j \sin \left(2 \pi k \frac{t}{N}\right)\right), t \in Z
$$

where, $X_{t}$ is the water surface elevation measured at time $t$, $N$ is the length of the gauge data time-series for a given lake; $k$ is the frequency; and $A_{k}$ is the magnitude of the time-series signal at frequency $k$. In Equation (3), $j$ is the imaginary number ${ }^{[30]}$. After the transformation, a plotting of $\left|A_{k}\right|$ versus frequency $k$ gives a spectral representation of the original signal.

More interestingly, the cumulative sum of $\left|A_{k}\right|$ over frequency $k$ provides information on how much of the variation in the water-level dynamics is confined to a given frequency threshold. In other words, the cumulative sum of $\left|A_{k}\right|$ normalized to the total sum indicates the fraction of the variation (i.e., energy or information) in the original time-series below a specified frequency $p$ :

$$
D_{p}=\sum_{k=0}^{p}\left|A_{k}\right| / \sum_{n=0}^{N-1}\left|A_{k}\right|
$$

where, $p$ again is the specified frequency limit and the denominator $\sum_{n=0}^{N} E_{n}$ represents the total energy of the whole time series. For example, if $p$ is chosen to correspond to a year, a value of 0.60 for $D_{p}$ means that $60 \%$ of the variation in the time series occurs beyond the annual cycle whereas the other $40 \%$ are intra-annual variation.

The particular implementation of the Fourier transform we selected is the Guass-Vanicek algorithm ${ }^{[35]}$. Although the standard Fourier transforms (e.g., fast Fourier transform) are well established, they can only handle time-series data measured at regular time intervals and does not allow for missing data. However, in many cases, gauge measurements used here have data gaps of varying length. These data limitations were directly circumvented by the Guass-Vanicek algorithm ${ }^{[35]}$, which performs the Fourier transform by switching to a least-square regression angle. That is, the parametric model of Equation (3) was fitted to the data with the parameters $\left|A_{k}\right|$ estimated using the least-square method.

Guass-Vanicek transform was applied to conduct frequency analysis in two fashions. Firstly, the repeat cycle of ICESat are $91 \mathrm{~d}$ and are divided into sub-cycles of $33 \mathrm{~d}$ and $29 \mathrm{~d}$. Lakes with a span shorter than $0.22^{\circ}$ in latitude could be passed only once by ICESat in a campaign. Therefore, the shortest repeat cycles of one lake were considered to be $60 \mathrm{~d}, 90 \mathrm{~d}, 120 \mathrm{~d}$ and $215 \mathrm{~d}$ (from the end of the former campaign to the start of the 
latter one). Secondly, the revisit periods or frequencies were identified corresponding to a value in $D_{p}$ of $0.9,0.8$, 0.7 and 0.6 , respectively.

\section{Results and discussion}

\subsection{Accuracy assessment of elevation derived from} ICESat

Locations of ICESat footprints covering the test area are shown in Figure 2a. After data processing and correction, only 24 footprints were left to validate the elevations. The result is shown in Figure $2 \mathrm{~b}$. All the differences between the ground elevations from GLAH14 and the elevations from the Lidar DEM varied from $-0.269 \mathrm{~m}$ to $0.267 \mathrm{~m}$. $R$ between ground elevations from GLAH14 and the Lidar DEM was 0.999 and the $R M S E$ was $0.164 \mathrm{~m}$.

The strong correlation between GLAH14 and the airborne Lidar DEM is also depicted in Figure 2b. The maximum difference between the two occurred at the boundary of the test area. This may be attributed to the exclusion of the Lidar DEM pixels outside the test area but covered by ICESat footprints. Compared to the use of lake surfaces as references, low-relief lands have stable topography and the assessment results provide a realistic estimate of the ranging accuracy of ICESat for water surfaces. The relative small errors stress the great potential of ICESat for accurately measuring water levels.

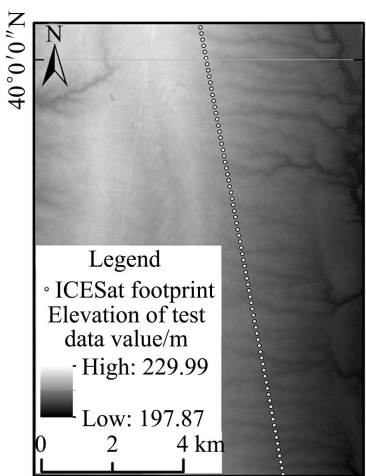

a. Lidar DEM from NED and ICESat footprints

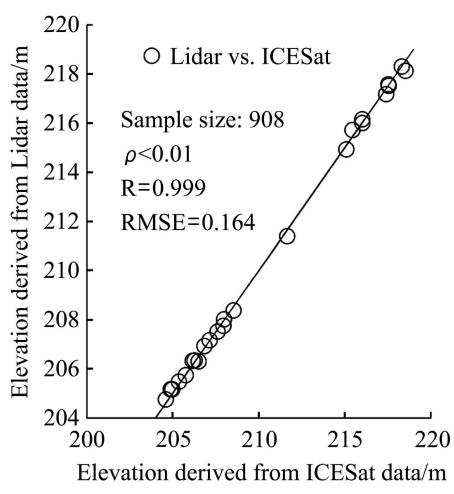

b. Scatterplot of ICESat-derived vs airborne lidar elevations
Note: The background image is the Lidar DEM image of the test area. The white dots show the position of ICESat footprints in the area.

Figure 2 ICESat footprints on the test area with gentle terrain near Champaign, IL, and test result of ICESat ranging accuracy

\subsection{Trend analysis}

Across the conterminous US, only 361 lakes were identified to have ICEsat measurement for two or more ICESat passes. The locations of these water bodies are shown in Figure 3. For the large lakes such as Superior Lake with a span about $3^{\circ}$ in latitude and $8^{\circ}$ in longitude, ICESat/CLAS could visit it up to 14 times within one campaign. Except for the Great Lakes, Great Salt Lake, Lake Tahoe, Red Lake and Lake of the Woods, all the other lakes were with less than 10 passes, with a time span of 2-6 a. Most of the lakes had one or two passes within one year and the data were often acquired in different seasons.

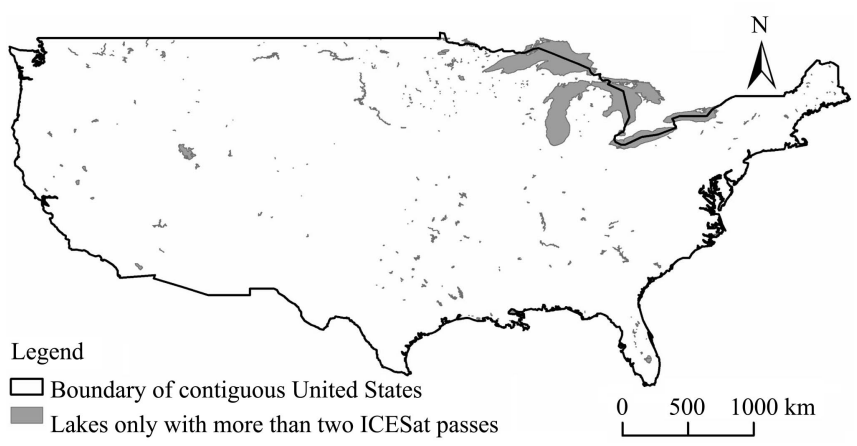

Figure 3 A US map with selected lakes that have more than two ICESat passes

The pixel size of our Landsat water mask was smaller than ICESat's footprint size. This better resolving ability helped to reduce the risks of including several different small lakes in the same polygons, as contrasted to those previous studies that often relied on MODIS-based water masks. This decreased the erroneous omission and commission errors and allowed incorporating more ICESat data. However, even though the mask enabled detecting more small lakes, the number of lakes measured by ICESat more than twice was too limited. A potential contributing factor is the rigorous data filtering criteria because multiple data quality flags were considered, such as saturation effects, reflectivity, latitude quality, gain values, and cloud condition. Our selected data were more reliable and the workflow will provide a feasible way to extract the elevations from ICESat-2 data for future work.

Linear regression was applied to all the 361 lakes and the resulting slopes indicated the trends in lake water-level variations. The significance of the inferred trends was tested by the Student $t$-test. A histogram of the $p$-value for test was shown in Figure 4 . Of all the 
361 lakes, only 20 lakes had a $p$-value $\leq 0.05$. That is, ICESat detected a meaningful trend in water level for only 20 lakes across the US.

Of the 361 lakes, only 50 had coincident elevation observations from both ICEsat and gauges. A surprising result to us is that for a large fraction of these lakes, the trends detected from ICESat and gauge stations were opposite (Table 2). For example, when comparing the trends in water level across the ICESat lifespan, 16 lakes out of the 50 lakes showed opposite trends between ICESat and gauge data (i.e., Slope $v s$. Trend1 in Table 2). Even when we narrowed down our analysis by considering ICESat and gauge data with absolute temporal coincidence, ICESat data still failed to estimate the signs in water-level change for 10 lakes (i.e., Slope $v s$. Trend2 in Table 2). Overall, over the conterminous US, ICESat failed to correctly monitor the real trends in water-level dynamics for most of the lakes.

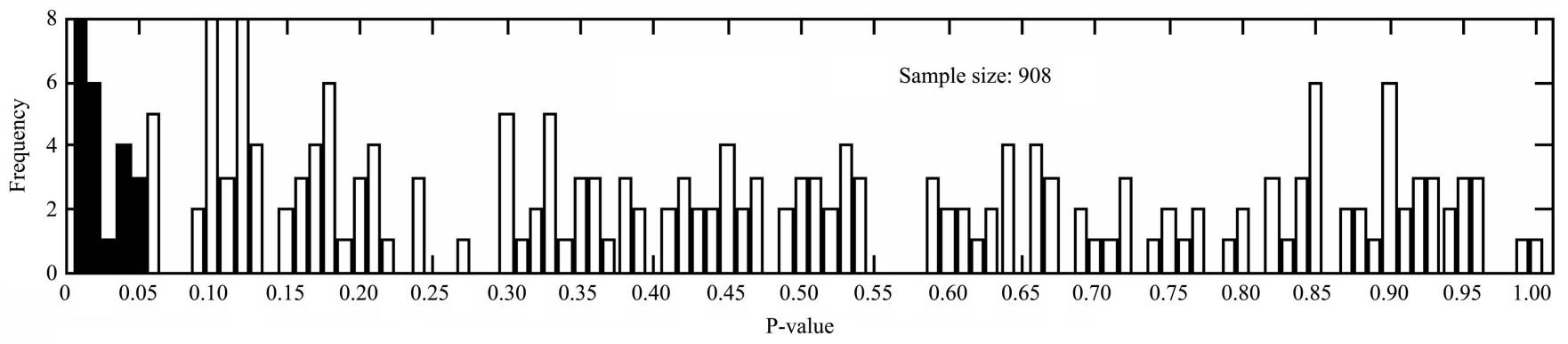

Note: Those lakes with a $p$-value less than 0.05 are highlighted in black.

Figure 4 Frequency of the $p$-values testing the signfiicance of the ICESat-detected water level trends

Table 2 Information of lakes and the results of linear regressions

\begin{tabular}{|c|c|c|c|c|c|c|c|}
\hline Lake Name & Pass/a & Slope & $p$ value & $R^{2}$ & State & Trend 1 & Trend 2 \\
\hline Devils & $7 / 5$ & -0.0003 & 0.1651 & 0.3455 & ND & 0.0001 & -0.0013 \\
\hline Toledo & $6 / 5$ & -0.0002 & 0.8689 & 0.0077 & $\mathrm{TX}$ & 0.0001 & -0.0004 \\
\hline Granbury & $3 / 2$ & 0.0001 & 0.7064 & 0.1981 & $\mathrm{TX}$ & -0.0008 & 0.0002 \\
\hline Squaw Creek & $4 / 4$ & -0.0003 & 0.3274 & 0.4524 & $\mathrm{TX}$ & 0.0001 & -0.0005 \\
\hline Stillhouse Hollow & $4 / 3$ & -0.0001 & 0.9074 & 0.0086 & $\mathrm{TX}$ & -0.0004 & 0.0002 \\
\hline Great Salt & $22 / 6$ & 0.0003 & 0.1058 & 0.1255 & UT & -0.0004 & 0.0006 \\
\hline Salton Sea & $7 / 4$ & -0.0004 & 0.0483 & 0.5746 & $\mathrm{CA}$ & 0.0010 & 0.0013 \\
\hline Upper Klamath & $7 / 4$ & 0.0004 & 0.6414 & 0.0468 & OR & -0.0003 & 0.0021 \\
\hline Moses & $2 / 2$ & -0.0050 & - & - & WA & 0.0001 & -0.0160 \\
\hline Houghton & $4 / 2$ & 0.0001 & 0.7971 & 0.0412 & MI & -0.0001 & 0.0005 \\
\hline Higgins & $4 / 3$ & 0.0000 & 0.9875 & 0.0002 & MI & -0.0001 & 0.0005 \\
\hline Darling & $7 / 4$ & -0.0011 & 0.0039 & 0.8365 & ND & -0.0022 & -0.0036 \\
\hline Mille Lacs & $6 / 4$ & -0.0003 & 0.0055 & 0.8816 & $\mathrm{MN}$ & -0.0005 & -0.0010 \\
\hline Havasu & $4 / 4$ & -0.0009 & 0.0177 & 0.9649 & $\mathrm{CA}$ & -0.0001 & -0.0024 \\
\hline Minnehaha & $6 / 4$ & -0.0004 & 0.1203 & 0.4922 & FL & -0.0024 & -0.0012 \\
\hline Saint Clair & $6 / 4$ & 0.0002 & 0.3261 & 0.2381 & MI & 0.0001 & -0.0001 \\
\hline Possum Kingdom & $2 / 2$ & -0.0009 & - & - & $\mathrm{TX}$ & 0.0016 & -0.0053 \\
\hline R. B. Russell & $3 / 2$ & 0.0001 & 0.8818 & 0.0341 & $\mathrm{SC}$ & -0.0019 & 0.0001 \\
\hline Tuttle Creek & $2 / 2$ & -0.0017 & - & - & $\mathrm{KS}$ & 0.0008 & -0.0065 \\
\hline Michigan & $45 / 7$ & -0.0414 & 0.3092 & 0.0240 & WI & -0.0001 & 0.0048 \\
\hline
\end{tabular}

Note: Trend1 is the slope of lake level linear regression based on the Gau1. Trend2 is the slope of linear regression based on Gau2. Slope is slope of linear regression based on elevations derived from ICESat.

\subsection{Frequency analysis to identify required revisit periods}

The failure of ICESat to detect trends in water-level dynamics is partially explained by the results from our frequency analysis. For example, assuming a revisit cycle of $90 \mathrm{~d}$ (i.e., a frequency of 1/90 d-1), ICESat would be able to capture only $<40 \%$ of the true dynamics for $51.98 \%$ of the US lakes examined (Figure $5 \mathrm{~b}$ ). If 
revisiting less frequently, the likelihood to recover true dynamics by ICESat become even less probable (Figures

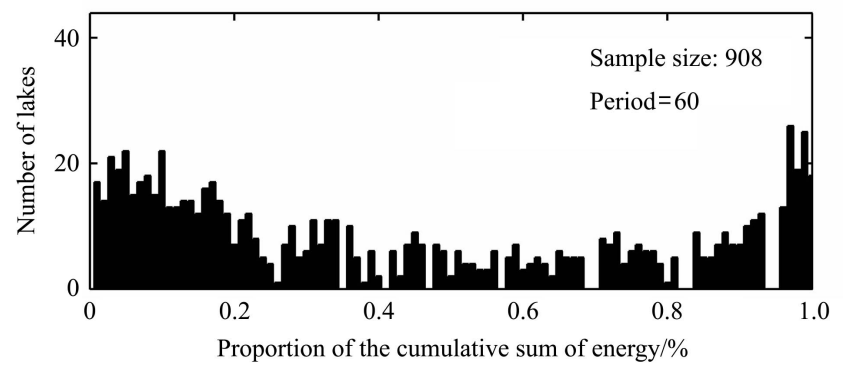

a Proportion of the cumulative sum of energy when period $=60$

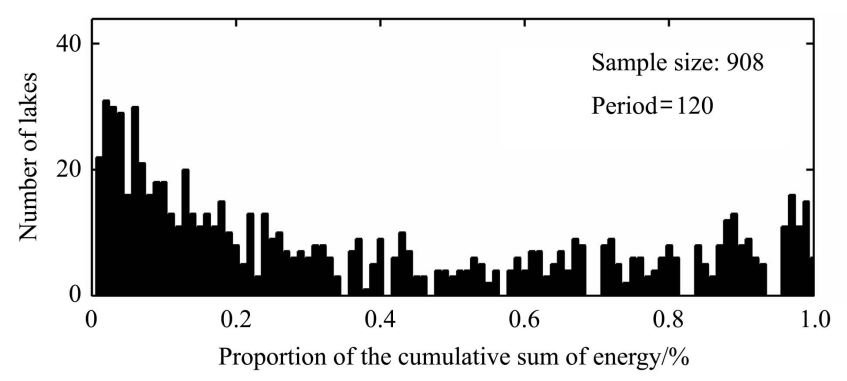

c Proportion of the cumulative sum of energy when period $=120$
$5 \mathrm{c}$ and $5 \mathrm{~d}$ for a revisit period of $120 \mathrm{~d}$ and $215 \mathrm{~d}$, respectively).

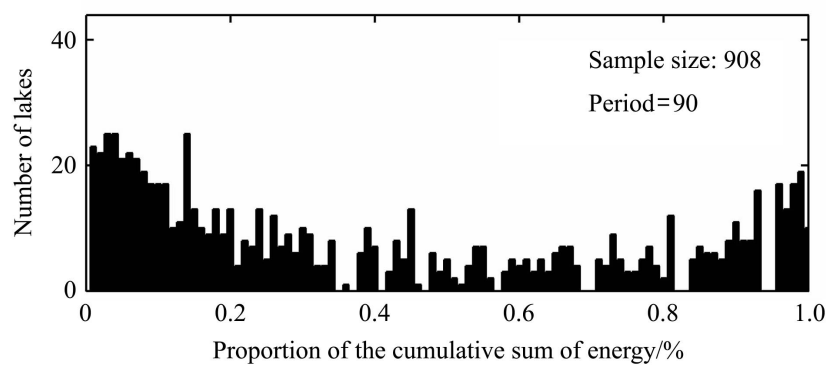

b Proportion of the cumulative sum of energy when period $=90$

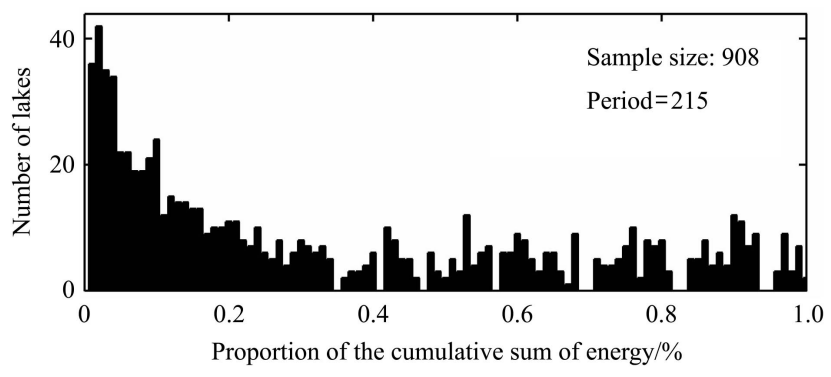

d Proportion of the cumulative sum of energy when period $=215$

Figure 5 Histogram of proportion of the cumulative sum of energy versus the number of lakes

Apparently, the shorter the revisit period, the more likely ICESat or satellite laser altimeters can recover the true water surface dynamics (Figure 5 and Table 3). If revisiting every $215 \mathrm{~d}$, ICESat can recover only $60 \%$ of the variation in gauge-observed lake dynamics for $25 \%$ of the US lakes examined; if shortening the revisit period to $60 \mathrm{~d}$, ICESat would capture $60 \%$ of the true variation for a larger fraction of lakes, $35 \%$. Because sixty days was the shortest revisit period of ICESat in its operation, the use of existing ICESat would fail to detect season dynamics for almost $65 \%$ of the lakes. Alternately speaking, existing ICESat may find valid use only for those lakes that are large enough and re-measured multiple times by ICESat in every campaign.

Table 3 Proportion of tested lakes occupying $60 \%$ of energy under four measuring periods

\begin{tabular}{ccccc}
\hline $\begin{array}{c}\text { Period } / \mathrm{d} \\
\text { Sample size: } 908\end{array}$ & 60 & 90 & 120 & 215 \\
\hline Percentage of Lakes/\% & 34.64 & 31.64 & 30.40 & 24.60 \\
\hline
\end{tabular}

In addition, we identified the minimum requirements for revisit cycles if the water-level dynamics of a certain fraction of lakes need to be detected at a certain significance level. Our hypothetical analyses suggested that to confidently track water-level dynamics from the space, satellite laser altimetry ideally should have a revisit cycle less than a week (Figure 6). As in Figure 6a, to capture $90 \%$ (i.e., $D_{p}=0.9$ ) of the water-level variation, even a revisit cycle as short as $10 \mathrm{~d}$ guarantees that only $0.7 \%$ of the lakes can be successfully monitored; if increasing the revisit frequency to $4 \mathrm{~d}$, there will be $8 \%$ of the lakes to be adequately monitored with $90 \%$ of water-level variations reliably captured. The numbers or proportions of lakes that can be successfully monitored at other significant levels (i.e., $D_{p}=0.6,0.7$, and 0.8 ) are summarized for a variety of revisit cycles in Table 4 . Overall, these results highlight that ICESat or its near-future successors are unlikely to have significant roles to play in monitor water surface dynamics due to insufficient temporal coverage.

For Level 1 ( $\left.D_{p}=0.9\right)$, the best measuring periods of 255 lakes were every two days. For Level $2\left(D_{p}=0.8\right)$, the best measuring periods of 283 lakes were every $3 \mathrm{~d}$. For Level $3\left(D_{p}=0.7\right)$, the best measuring periods of 209 lakes were every $3 \mathrm{~d}$. At Level $4,\left(D_{p}=0.6\right)$, the best measuring periods of 131 lakes are every $4 \mathrm{~d}$.

Table 4 shows that, for Level 1, the ideal measuring frequency is every $2 \mathrm{~d}$, for Level 2 and Level 3, the ideal measuring frequency is every $3 \mathrm{~d}$ and for Level 4 , the ideal measuring frequency is every $4 \mathrm{~d}$. 


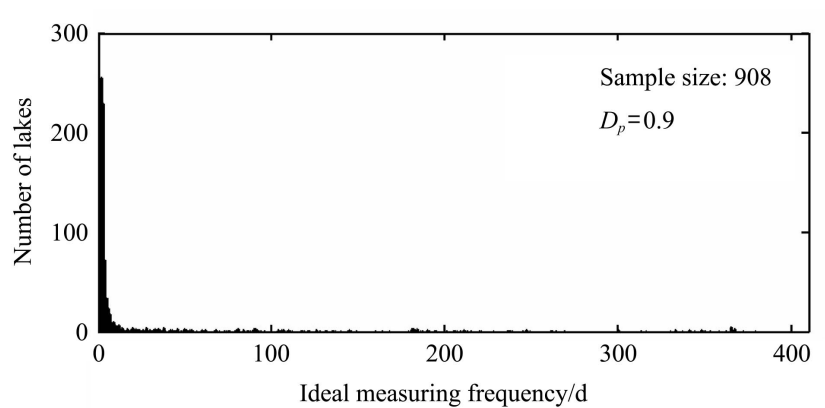

a The ideal measuring frequencies when $D_{p}=0.9$

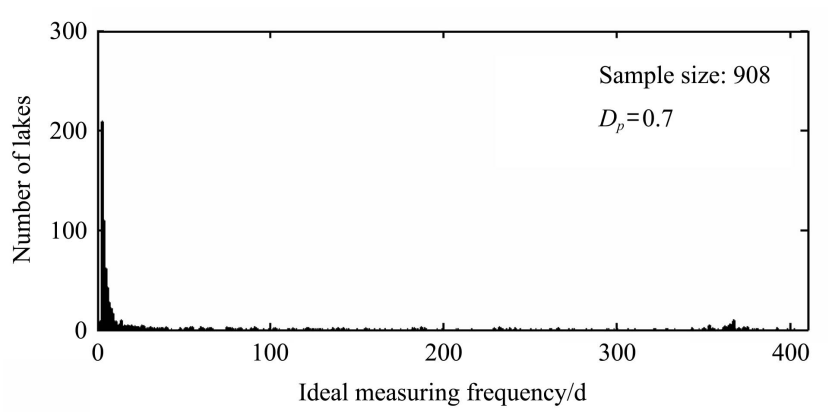

c The ideal measuring frequencies when $D_{p}=0.7$

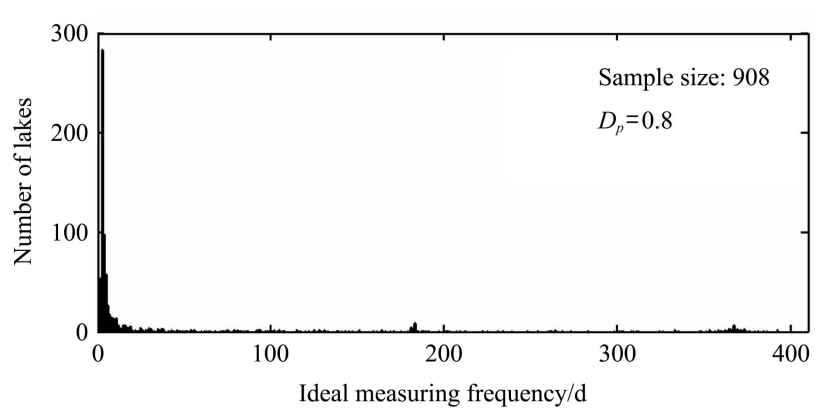

b The ideal measuring frequencies when $D_{p}=0.8$

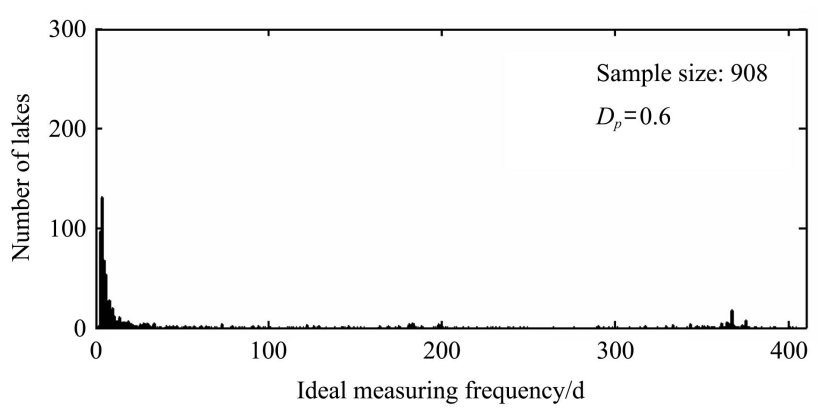

d The ideal measuring frequencies when $D_{p}=0.6$

Figure 6 Histogram of the ideal revisit period/frequency versus the number of lakes

Table 4 Number of lakes with the best measuring periods of less than $10 \mathrm{~d}$ under four levels

\begin{tabular}{cccccccccc}
\hline \multirow{2}{*}{ Levels } & \multicolumn{8}{c}{ The best measuring periods/d } \\
\cline { 2 - 9 } & 2 & 3 & 4 & 5 & 6 & 7 & 8 & 9 & 10 \\
\hline $1\left(D_{p}=0.9\right)$ & 255 & 229 & 72 & 34 & 24 & 18 & 8 & 10 & 7 \\
$2\left(D_{p}=0.8\right)$ & 54 & 283 & 98 & 58 & 27 & 18 & 15 & 14 & 6 \\
$3\left(D_{p}=0.7\right)$ & 9 & 209 & 110 & 62 & 43 & 28 & 22 & 17 & 9 \\
$4\left(D_{p}=0.6\right)$ & 2 & 97 & 131 & 68 & 54 & 26 & 28 & 17 & 20 \\
\hline
\end{tabular}

Note: Sample size: 908 .

\section{Conclusions}

ICESat data were combined with gauge elevation data to assess how reliably ICESat can be used as a mapping tool to routinely monitor water surface dynamics. Our evaluation of ICESat data re-affirmed its superior accuracy in mapping surface elevation, with an estimated error of only $0.16 \mathrm{~m}$; however, this high precision does not ensure the utility of ICESat for tracking water-level dynamics because of its limited temporal sampling. Lake level variations in the conterminous United States and its potential and limitation were investigated. For the large lakes such as the Great Lakes the trends extracted from ICESat derived elevations were in good agreements with the gauge data. ICESat data has the potential to monitor the daily, monthly, seasonally, annual variation rules of water level. However for the other lakes, ICESat failed to show even the inter annual trends. If the lakes were measured every five days or less, $60 \%$ of the information of lakes could be extracted. Under the current condition, the periods of ICESat and ICESat-2 are from $60 \mathrm{~d}$ to $215 \mathrm{~d}$ for small lakes and only $41 \%$ of the lakes could get the information more than $60 \%$. Although they have a relatively high temporal resolution, its periods to cover certain lakes are quite long so that it is still hard to get the trends from these data. But satellite laser altimetry may still find important use in cases where lakes, especially large ones, are known to have systematic trends in water level yet with limited seasonal variability.

\section{Acknowledgments}

This work was partly supported by the Open Research Fund from the State Key Laboratory of Digital Earth Science, Institute of Remote Sensing and Digital Earth, Chinese Academy of Science (OFSLRSS201604), a Microsoft Azure Research Award (CRM:0518513), and China Scholarship Council (CSC No.:201406170122)

\section{[References]}

[1] Pan F, Liao J, Li X, Guo H. Application of the inundation area-lake level rating curves constructed from the SRTM DEM to retrieving lake levels from satellite measured inundation areas. Computers and Geosciences, 2013; 52: 
$168-176$.

[2] Hansen M C, Potapov P V, Moore R, Hancher M, Turubanova S A, Tyukavina A, et al. High-resolution global maps of 21 st-century forest cover change. Science, 2013; 342(6160): 850-853.

[3] Mercier F, Cazenave A, Maheu C. Interannual lake level fluctuations (1993-1999) in Africa from Topex/Poseidon: connections with ocean-atmosphere interactions over the Indian Ocean. Global and Planetary Change, 2002; 32: 23.

[4] Guo M, Wu W, Zhou X, Chen Y, Li J. Investigation of the dramatic changes in lake level of the Bosten Lake in northwestern China. Theoretical and Applied Climatology, 2014; 119(1-2): 341-351.

[5] $\mathrm{Wu} \mathrm{Y}, \mathrm{Zhu} \mathrm{L}$. The response of lake-glacier variations to climate change in Nam Co Catchment, central Tibetan Plateau, during 1970-2000. Journal of Geographical Sciences, 2008; 18(2): 177-89.

[6] Song C Q, Huang B, Ke L H, Richards K S. Seasonal and abrupt changes in the water level of closed lakes on the Tibetan Plateau and implications for climate impacts. Journal of Hydrology, 2014; 514: 131-144.

[7] Ponchaut F, Cazenave A. Continental lake level variations from Topex/Poseidon (1993-1996). Comptes Rendus de 1 Académie des Sciences - Series IIA - Earth and Planetary Science, 1998; 326(1): 13-20.

[8] Wang X W, Gong P, Zhao Y Y, Xu Y, Cheng X, Niu Z G, et al. Water-level changes in China's large lakes determined from ICESat/GLAS data. Remote Sensing of Environment, 2013; 132: 131-144.

[9] Phan V H, Lindenbergh R, Menenti M. ICESat derived elevation changes of Tibetan lakes between 2003 and 2009. International Journal of Applied Earth Observation and Geoinformation, 2012; 17: 12-22.

[10] Jarihani A J, Callow J N, Johansen K, Gouweleeuw B. Evaluation of multiple satellite altimetry data for studying inland water bodies and river floods. Journal of Hydrology, 2013; 505: 78-90.

[11] Song C, Huang B, Ke L, Richards K S. Remote sensing of alpine lake water environment changes on the Tibetan Plateau and surroundings: A review. ISPRS Journal of Photogrammetry and Remote Sensing, 2014; 92: 26-37.

[12] Zhang G, Xie H, Kang S, Yi D, Ackley S F. Monitoring lake level changes on the Tibetan Plateau using ICESat altimetry data (2003-2009). Remote Sensing of Environment, 2011; 115(7): 1733-1742.

[13] Muala E, Mohamed Y, Duan Z, van der Zaag P. Estimation of reservoir discharges from Lake Nasser and Roseires Reservoir in the Nile Basin using satellite altimetry and imagery data. Remote Sensing, 2014; 6(8): 7522-45.

[14] Kleinherenbrink $\mathrm{M}$, Lindenbergh $\mathrm{R}$ C, Ditmar $\mathrm{P}$ G.
Monitoring of lake level changes on the Tibetan Plateau and Tian Shan by retracking Cryosat SARIn waveforms. Journal of Hydrology, 2015; 521: 119-131.

[15] Santos da Silva J, Calmant S, Seyler F, Rotunno Filho O C, Cochonneau G, Mansur W J. Water levels in the Amazon basin derived from the ERS 2 and ENVISAT radar altimetry missions. Remote Sensing of Environment, 2010; 114(10): 2160-2181.

[16] Zhao K, Popescu S, Nelson R. Lidar remote sensing of forest biomass: a scale-invariant estimation approach using airborne lasers. Remote Sensing of Environment, 2009; 113(1): 182-196.

[17] Herzfeld U C, Wallin B. Spatio-temporal analysis of surface elevation changes in Pine Island Glacier, Antarctica, from ICESat GLAS data and ERS-1 radar altimeter data. Annals of Glaciology, 2014; 55(66): 248-258.

[18] Betbeder J, Gond V, Frappart F, Baghdadi N, Briant G, Bartholomes E. Mapping of central Africa forested wetlands using remote sensing. IEEE Journal of Selected Topics in Applied Earth Observations \& Remote Sensing, 2014; 7(2): 531-542.

[19] Tang H, Brolly M, Zhao F, Dubayaha R. Deriving and validating Leaf Area Index (LAI) at multiple spatial scales through lidar remote sensing: A case study in Sierra National Forest, CA. Remote Sensing of Environment, 2014; 143(3): $131-141$

[20] Luthcke S B, Rowlands D D, Williams T A, Sirot M. Reduction of ICESat systematic geolocation errors and the impact on ice sheet elevation change detection. Geophysical Research Letters, 2005; 32(21). DOI: 10.1029/2005GL023689.

[21] García M, Popescu S, Riaño D, Zhao K, Neuenschwander A, Agca $M$, et al. Characterization of canopy fuels using ICESat/GLAS data. Remote Sensing of Environment, 2012; 123(1): 81-89.

[22] Zwally H J, Schutz B, Abdalati W, Abshire J, Bentley C, Brenner A, et al. ICESat's laser measurements of polar ice, atmosphere, ocean, and land. Journal of Geodynamics, 2002; 34(3-4): 405-445.

[23] Abshire J B, Sun X L, Riris H, Sirota J M, McGarry J F, Palm S, et al. Geoscience laser altimeter system (GLAS) on the ICESat mission: On-orbit measurement performance. Geophysical Research Letters, 2005; 32(21): 4p.

[24] Alsdorf D, Birkett C, Dunne T, Melack J, Hess L. Water level changes in a large Amazon lake measured with spaceborne radar interferometry and altimetry. Geophysical Research Letters, 2001; 28(14): 2671-4.

[25] Chipman J W, Lillesand T M. Satellite-based assessment of the dynamics of new lakes in southern Egypt. International Journal of Remote Sensing, 2007; 28(19): 4365-79. 
[26] Baghdadi N, Lemarquand N, Abdallah H, Bailly J S. The relevance of GLAS/ICESat elevation data for the monitoring of river networks. Remote Sensing, 2011; 3(12): 708-720.

[27] Hall A C, Schumann G J P, Bamber J L, Bates P D, Trigg M A. Geodetic corrections to Amazon River water level gauges using ICESat altimetry. Water Resources Research, 2012; 48(6). DOI: 10.1029/2011WR010895.

[28] van Dijk A I J M, Peña-Arancibia J L, Wood E F, Sheffield J, Beck H E. Global analysis of seasonal streamflow predictability using an ensemble prediction system and observations from 6192 small catchments worldwide. Water Resources Research, 2013; 49(5): 2728-2746.

[29] Wu H, Wang N, Jiang X, Guo Z. Variations in water level and glacier mass balance in Nam Co lake, Nyainqentanglha range, Tibetan Plateau, based on ICESat data for 2003-09. Annals of Glaciology, 2014; 55(66): 239-247.

[30] Dewberry. Final Report of the National Enhanced Elevation Assessment, 2011.

[31] Meng X, Currit N, Zhao K. Ground filtering algorithms for airborne LiDAR data: A review of critical issues. Remote Sensing, 2010; 2(3): 833-860.
[32] Wang X, Cheng X, Li Z, Huang H, Niu Z, Li X, et al. Lake water footprint identification from time-series ICESat/GLAS data. IEEE Geoscience and Remote Sensing Letters, 2012; 9(3): 333-337.

[33] Gao L, Liao J, Shen G. Monitoring lake-level changes in the Qinghai-Tibetan Plateau using radar altimeter data (2002-2012). Journal of Applied Remote Sensing, 2013; 7(23): 8628-8652.

[34] Popescu S C, Zhao K, Neuenschwander A, Lin C. Satellite lidar vs. small footprint airborne lidar: Comparing the accuracy of aboveground biomass estimates and forest structure metrics at footprint level. Remote Sensing of Environment, 2011; 115(11): 2786-2797.

[35] Zhao K, Popescu S. Lidar-based mapping of leaf area index and its use for validating GLOBCARBON satellite LAI product in a temperate forest of the southern USA. Remote Sensing of Environment, 2009; 113(8): 1628-1645.

[36] Cornette J L. Gauss-Vanícek and Fourier transform spectral analyses of marine diversity. Computing in Science \& Engineering, 2007; 9(4): 61-63. 